\title{
PROFIL EKG PASIEN HIPERTENSI DI POLIKLINIK JANTUNG
}

\section{(ECG Profile of Hypertension patients in Outpatient Cardiac Unit)}

\author{
Fira Soraya*, Elyana Asnar STP**, Muhammad Aminuddin*** \\ *Fakultas Kedokteran, Universitas Airlangga, Surabaya \\ **Departemen Faal Kedokteran, Fakultas Kedokteran, Universitas Airlangga, Surabaya \\ ***SMF Kardiologi Dan Kedokteran Vaskular, RSUD Dr. Soetomo, Surabaya \\ Email: firasorayaemail@gmail.com
}

\begin{abstract}
ABSTRAK
Pendahuluan: Sebanyak 31,7\% penduduk Indonesia memiliki hipertensi. Hipertensi dapat mengakibatkan perubahan pada anatomi dan atau fungsi jantung yang dapat menyebabkan morbiditas dan atau mortalitas. Perubahan itu sendiri dapat dideteksi dengan elektrokardiografi (EKG). Berdasarkan alasan tersebut, tujuan dari studi ini adalah mengetahui profil EKG pasien hipertensi di Poliklinik Jantung RSUD Dr. Soetomo Surabaya. Metode: Studi ini merupakan penelitian deskriptif observasional. Sampel penelitian didapatkan melalui data primer dan data sekunder dengan menggunakan teknik sampel total selama periode 1-31 Maret 2015. Data yang terkumpul diolah berdasarkan jenis kelamin, usia dan ada tidaknya hipertrofi ventrikel kiri jantung. Hasil: Terdapat 140 pasien hipertensi selama periode 1-31 Maret 2015. Prevalensi hipertensi didapatkan sama antara pria dan wanita. Prevalensi rentang usia tertinggi pasien hipertensi adalah usia 51-60 tahun. Dua Hasil EKG menunjukkan hipertrofi ventrikel kiri, dimana kedua hasil tersebut terdapat pada pria usia 55 tahun dan 61 tahun, dan 138 hasil EKG menunjukkan selain hipertrofi ventrikel kiri, seperti aritmia dan fibrilasi atrial. Diskusi: Hasil yang diperolah dan telah diolah menunjukkan hasil yang sama antara pria dan wanita, dimana menurut beberapa penelitian yang telah ada terdapat perbedaan antara pria dan wanita. Hal ini kemungkinan dapat dipengaruhi oleh beberapa faktor.
\end{abstract}

Kata kunci: hipertensi, EKG, hipertrofi ventrikel kiri

\begin{abstract}
Introduction: It covers $31.7 \%$ of people with hypertension in Indonesia. Hypertension can cause changes in the anatomy and/or function of the heart, that may cause morbidity and/or mortality. The changes itselves can be diagnosed with electrocardiography (ECG). Based on that background, the objective of this study is to recognize the ECG profile of hypertension patients in Cardiology Outpatient Clinic RSUD Dr. Soetomo Surabaya. Method: The design of this study was observational descriptive study. The samples were obtained through primary and secondary data from patients' medical history within the period of 1 st until 31st March. The collected data was managed based on gender, age and the present of left ventricular hypertrophy. Result: There were 140 hypertension patients throughout this study period. The prevalence of hypertension was the same between men and women. The highest prevalency of hypertension was in age 51 to 60 . Two ECG results showed left ventricular hypertrophy and 138 ECG results showed other than left ventricular hypertrophy, such as arrhythmia and atrial fibrillation. Discussion: The results show that there is no different between men and women, where other previous researches show that the result is different between men and women. This can be caused by many factors.
\end{abstract}

Keywords: hypertension, ECG, left ventricular hypertrophy

\section{PENDAHULUAN}

Penyakit tidak menular (PTM) menjadi penyebab utama kematian secara global. Data WHO menunjukkan bahwa dari 57 juta kematian yang terjadi di dunia pada tahun 2008, sebanyak 36 juta kematian disebabkan oleh PTM. Penyakit tidak menular tersebut antara lain adalah penyakit jantung, stroke, kanker, penyakit pernapasan kronis, penyakit pencernaan dan diabetes. Salah satu penyakit tidak menular yang cukup memengaruhi angka kesakitan dan angka kematian adalah penyakit kardiovaskular (PKV). Tahun 2008 diestimasikan 17,3 juta kematian yang terjadi di negara maju dan negara berkembang disebabkan oleh PKV, dengan sekitar $80 \%$ kematian terjadi di negara berpendapatan rendah dan sedang. Tahun
2009, penyakit jantung menduduki peringkat tertinggi sebagai penyakit penyebab kematian. Di Indonesia, penyebab kematian terbanyak adalah penyakit kardiovaskular, yaitu sebesar $30 \%$ dan disusul dengan penyakit menular, maternal, perinatal dan gizi sebesar $28 \%$.

Riskesdas pada tahun 2007 menyatakan bahwa salah satu PTM yang memiliki prevalensi cukup tinggi di Indonesia adalah hipertensi, yakni 31,7\%. Hipertensi merupakan salah satu masalah kesehatan masyarakat yang terjadi di negara maju maupun negara berkembang. Hasil pencatatan dan pelaporan rumah sakit (SIRS, Sistem Informasi Rumah Sakit) menunjukkan bahwa di Indonesia hipertensi menjadi kasus baru terbanyak PTM penyebab rawat jalan di rumah sakit, baik pada 
tahun 2009 (3,66\%) maupun $2010(3,13 \%)$. Hipertensi menempati urutan pertama jumlah kasus PTM penyebab rawat inap di rumah sakit, baik pada tahun 2009 (4,19\%) maupun 2010 (4,39\%). Case Fatality Rate (CFR) hipertensi di rumah sakit di Indonesia mengalami peningkatan $0,5 \%$ pada tahun 2010. Tingkat kefatalan (CFR) hipertensi di rumah sakit di Indonesia pada tahun 2009 sebesar 3\%, sedangkan pada tahun 2010 sebesar 3,5\%. Seseorang dikatakan hipertensi jika memiliki tekanan darah sistolik $\geq 140$ $\mathrm{mmHg}$ dan tekanan darah diastolik $\geq 90 \mathrm{mmHg}$ (JNC-7 2003). Hipertensi bersama dengan obesitas, hiperlipidemia, dan hiperglikemia, yang dikenal dengan istilah sindrom metabolik, dapat meningkatkan risiko PKV.

Hipertensi merupakan salah satu faktor risiko terjadinya kerusakan pada organ jantung yang penting baik bagi pria maupun wanita. Penelitian-penelitian terbaru melaporkan bahwa hipertrofi ventrikel kiri adalah perubahan tersering yang terjadi pada jantung akibat hipertensi dan dapat dideteksi melalui perekaman jantung dengan elektrokardiografi (EKG). Tujuan dari penelitian ini secara umum adalah mengetahui profil EKG pasien hipertensi di Unit Rawat Jalan Poliklinik Jantung RSUD Dr. Soetomo Surabaya periode 1-31 Maret 2015, terhitung 22 hari kerja. Selain itu penulis juga ingin mengetahui distribusi jenis kelamin dan usia pada pasien hipertensi di Unit Rawat Jalan Poliklinik Jantung RSUD Dr. Soetomo Surabaya periode 1-31 Maret 2015, terhitung 22 hari kerja.

\section{BAHAN DAN METODE}

Jenis penelitian yang digunakan dalam penelitian ini adalah penelitian potong lintang (cross-sectional) dengan menggunakan studi deskriptif observasional. Penelitian ini menggunakan data sekunder yang diambil dari rekam medik pasien, yaitu riwayat hipertensi, usia dan jenis kelamin pasien, serta data primer yaitu gambaran EKG terakhir pasien dan tekanan darah pasien saat itu yang diambil oleh dokter yang menangani pasien hipertensi di Unit Rawat Jalan Poliklinik Jantung RSUD Dr. Soetomo Surabaya periode 1-31 Maret 2015 dalam rentang waktu antara pukul 11.30-14.00 WIB. Data pasien yang diambil kemudian diolah dan dianalisis sesuai dengan kebutuhan penulis, seperti menggunakan uji Uji Signifikansi Mann
Whitney U untuk mengetahui adakah perbedaan yang bermakna antara hipertensi pada pria dan wanita. Variabel yang diteliti mencakup gambaran EKG pasien hipertensi, jenis kelamin dan usia pasien hipertensi.

\section{HASIL}

Penelitian ini dilakukan di Unit Rawat Jalan Poliklinik Jantung RSUD Dr. Soetomo Surabaya pada periode $1-31$ Maret 2015, terhitung 22 hari kerja dan dalam rentang waktu antara pukul 11.30-14.00 WIB. Selama penelitian didapatkan 140 subjek kasus pasien hipertensi yang dilakukan perekaman EKG di hari yang sama dengan pengambilan data pasien.

Tabel 1. Distribusi jenis kelamin dan usia pasien hipertensi

\begin{tabular}{cccc}
\hline Usia & Pria & Wanita & $\begin{array}{c}\text { Frekuensi } \\
(\mathrm{n}=140 \\
\text { pasien })\end{array}$ \\
\hline $21-30$ & 1 & 3 & 4 \\
$31-40$ & 0 & 4 & 4 \\
$41-50$ & & & \\
$41-44$ & 2 & 3 & 5 \\
$45-50$ & 8 & 13 & 21 \\
$51-60$ & 22 & 26 & 48 \\
$61-70$ & 26 & 15 & 41 \\
$71-80$ & 9 & 6 & 15 \\
$81-90$ & 1 & 1 & 2 \\
\hline Total & 69 & 71 & 140 \\
\hline
\end{tabular}

Distribusi jenis kelamin pasien hipertensi pada penelitian ini adalah pasien wanita (71 pasien pasien atau mencakup $50,72 \%$ dari total pasien) berjumlah lebih banyak daripada pasien pria (69 pasien atau mencakup 49,28\% dari total pasien). Distribusi usia pasien hipertensi pada penelitian ini yang terbanyak adalah pada rentang usia 51-60 tahun, yakni 48 pasien atau mencakup 34,29\% dari total pasien dan jumlah terendah adalah rentang usia 81-90 tahun sebanyak 2 pasien atau mencakup $1,43 \%$ dari total pasien. Rentang usia 21-30 tahun sebanyak 4 pasien atau mencakup $2,86 \%$ dari total pasien, rentang usia 31-40 tahun sebanyak 4 pasien atau mencakup 2,86\% dari total pasien, rentang usia 41-50 tahun sebanyak 26 pasien atau mencakup $18,57 \%$ dari total pasien, rentang usia 61-70 tahun sebanyak 41 pasien atau 
mencakup 29,28\% dari total pasien, dan rentang usia 71-80 tahun sebanyak 15 pasien atau mencakup $10,71 \%$ dari total pasien. Selanjutnya, untuk memudahkan pembahasan distribusi usia pasien hipertensi dibagi menjadi dua kelompok, yaitu $<45$ tahun dan $\geq 45$ tahun. Usia $<45$ tahun sebanyak 13 pasien $(9,29 \%)$ dan $\geq 45$ tahun sebanyak 127 pasien $(90,71 \%)$. Wanita usia $<45$ tahun lebih banyak menderita hipertensi dibanding dengan pria usia $<45$ tahun, sedangkan $\geq 45$ tahun jumlah wanita dan pria yang menderita hipertensi hampir sama.

Data TDS dan TDD pria dan wanita pada sampel penelitian ini kemudian diuji dengan

One-Sample Kolmogorov-Smirnov Test dan disimpulkan bahwa data tidak terdistribusi normal. Kemudian dilanjutkan dengan uji Mann Whitney U untuk menentukan tekanan darah pria dan wanita memiliki perbedaan yang signifikan atau tidak. Disimpulkan bahwa tekanan darah pria dan wanita memiliki perbedaan yang tidak signifikan atau dapat disimpulkan bahwa prevalensi tekanan darah pria dan wanita adalah sama. Hitungan rumus dapat dilihat pada lampiran III.

Tabel 2. Distribusi gambaran EKG pasien hipertensi

\begin{tabular}{lc}
\hline \multicolumn{1}{c}{ Gambaran EKG } & $\begin{array}{c}\text { Frekuensi } \\
(\mathrm{n}=140 \text { gambaran })\end{array}$ \\
\hline $\begin{array}{l}\text { Hipertrofi ventrikel kiri } \\
\text { Bukan hipertrofi } \\
\text { ventrikel kiri }\end{array}$ & 2 \\
\hline
\end{tabular}

Distribusi gambaran EKG pada penelitian ini mencakup hipertrofi ventrikel kiri dan selain hipertrofi ventrikel kiri. Gambaran EKG yang terbanyak adalah bukan hipertrofi ventrikel kiri, yakni sebesar 138 gambaran atau mencakup $98,57 \%$ dari total gambaran, dimana 138 gambaran tersebut terdiri dari gambaran EKG normal, aritmia, atrial fibrilasi dan gambaran-gambaran lain selain hipertrofi ventrikel kiri. Gambaran hipertrofi ventrikel kiri sebanyak 2 gambaran atau mencakup 1,43\% dari total gambaran, di mana hal yang khas ditemukan dalam kedua gambaran EKG tersebut yang menunjukkan gambaran hipertrofi ventrikel kiri adalah jumlah gelombang $\mathrm{S}$ pada lead V1 dengan gelombang $\mathrm{R}$ pada lead V5/V6 (dipilih yang lebih tinggi) $>35 \mathrm{~mm}$, hal ini sesuai dengan kriteria Sokolow-Lyon untuk hipertrofi ventrikel kiri.

Pasien yang memiliki gambaran hipetrofi ventrikel kiri tersebut berusia 55 tahun dan 61 tahun. Pasien yang berusia 55 tahun memiliki tekanan darah 140/100 $\mathrm{mmHg}$ dengan riwayat mengetahui hipertensi 5 tahun dan pasien 61 tahun memiliki tekanan darah $145 / 98 \mathrm{mmHg}$ dengan riwayat mengetahui hipertensi 10 tahun. Hal tersebut mendukung terjadinya hipertrofi ventrikel kiri. Data mengenai tekanan darah seluruh sampel dapat dilihat pada lampiran II.

Tabel 3. Distribusi riwayat diketahuinya hipertensi pasien hipertensi

\begin{tabular}{lc}
\hline $\begin{array}{c}\text { Riwayat Diketahuinya } \\
\text { Hipertensi }\end{array}$ & $\begin{array}{c}\text { Frekuensi } \\
(\mathrm{n}=140 \text { pasien })\end{array}$ \\
\hline Tidak mengetahui / lupa & 43 \\
Mengetahui & \\
0-3 tahun & 29 \\
4-6 tahun & 53 \\
7-9 tahun & 9 \\
10-12 tahun & 6 \\
\hline
\end{tabular}

Pasien hipertensi yang mengetahui bahwa ia menderita hipertensi sebelumnya lebih banyak daripada pasien yang tidak mengetahui atau lupa bahwa ia menderita hipertensi sebelumnya. Sebanyak 43 pasien atau mencakup $30,71 \%$ dari total pasien mengaku tidak tahu atau lupa bahwa ia menderita hipertensi sebelumnya dan terdapat 97 pasien mengetahui bahwa ia menderita hipertensi sebelumnya atau mencakup 69,29\% dari total pasien. Riwayat mengetahui memiliki hipertensi terdistribusi menjadi 4 kelompok, yaitu telah mengetahui memiliki hipertensi selama 0-3 tahun sebanyak 29 pasien atau mencakup $20,71 \%$ dari total pasien, telah mengetahui memiliki hipertensi selama 4-6 tahun sebanyak 53 pasien atau mencakup $37,86 \%$ dari total pasien, telah mengetahui memiliki hipertensi selama 7-9 tahun sebanyak 9 pasien atau mencakup $6,43 \%$ dari total pasien dan telah mengetahui memiliki hipertensi selama 10-12 tahun sebanyak 6 pasien atau mencakup 4,29\% dari total pasien.

\section{PEMBAHASAN}

Melalui uji perbedaan Mann Whitney U disimpulkan bahwa tidak ada perbedaan tekanan darah sistolik dan diastolik yang menjadi komponen dalam perhitungan 
hipertensi yang signifikan antara wanita dengan pria. Hal ini dapat disebabkan perbedaan jumlah wanita dan pria yang menjadi subjek penelitian ini tidak terlalu jauh berbeda. Selain itu, banyak dari subjek penelitian yang merupakan pasien lama atau telah lama mengetahui bahwa ia memiliki hipertensi sehingga dapat diasumsikan bahwa telah ada pengontrolan akan tekanan darah baik sistolik maupun diastolik sehingga tidak ditemukan perbedaan yang signifikan atau dapat disimpulkan bahwa prevalensi tekanan darah pria dan wanita adalah sama.

Berdasarkan data yang telah diolah, rentang usia yang paling banyak menderita hipertensi adalah pasien yang berusia 51-60 tahun yakni sebanyak 48 pasien $(34,29 \%)$. Rentang usia 61-70 tahun menempati urutan kedua dengan jumlah 41 pasien $(29,28 \%)$ dan rentang umur 41-50 tahun menempati urutan ketiga dengan jumlah 26 pasien (18,57\%). Selanjutnya, untuk memudahkan pembahasan distribusi usia pasien hipertensi dibagi menjadi dua kelompok, yaitu $<45$ tahun dan $\geq 45$ tahun. Usia <45 tahun sebanyak 13 pasien $(9,29 \%)$ terdiri dari 3 pasien pria dan 10 pasien wanita dan $\geq 45$ tahun sebanyak 127 pasien $(90,71 \%)$ terdiri dari 66 pasien pria dan 61 pasien wanita.

Pasien hipertensi akan meningkat prevalensinya seiring dengan penambahan usia (Rampal et al. 2008) Di Pulau Jawa, prevalensi pasien hipertensi terbanyak adalah rentang usia $\geq 45$ tahun (Setiawan 2006) Dalam penelitian lain yang dilakukan oleh (Pradono n.d, 2010). Prevalensi pasien hipertensi di daerah perkotaan lebih tinggi pada rentang usia $\geq 45$ tahun. Perubahan struktur pada pembuluh darah besar yang disebabkan oleh peningkatan tekanan darah sistolik dan mengakibatkan lumen menjadi lebih sempit dan dinding pembuluh darah menjadi lebih kaku akan meningkatkan risiko terjadinya hipertensi (Muhammadun 2010). Seiring dengan pertambahan usia, pembuluh darah akan menjadi lebih kaku dan menurunkan elastisitas pembuluh darah tersebut. Pembuluh darah yang menjadi lebih kaku dan menurunnya elastisitas memaksa darah pada setiap denyut jantung untuk melalui lumen yang sempit daripada biasanya (Susalit 2001). Hal ini yang menyebabkan pada usia pertengahan (>40 tahun), risiko untuk terjadi hipertensi meningkat (Krummel 2004).

Berdasarkan data dan gambaran EKG pasien hipertensi terdapat 2 pasien dengan hipertrofi ventrikel kiri, di mana kedua pasien tersebut adalah pria. Kedua pasien pria yang memiliki gambaran hipertrofi ventrikel kiri pada rekaman EKG berusia 55 tahun dan 61 tahun. Prevalensi gambaran EKG hipertrofi ventrikel kiri meningkat sesuai dengan peningkatkan umur, sedikit lebih dominan pada pria dan 1 dari 10 orang dalam rentang usia 30-62 tahun diduga memiliki hipertrofi ventrikel kiri selama 12 tahun (Kannel 1983). Hal tersebut sesuai dengan hasil yang didapat dalam penelitian ini, dimana terdapat 2 pasien pria berusia 55 tahun dan 61 tahun yang memiliki gambaran EKG hipertrofi ventrikel kiri. Hal yang khas ditemukan dalam gambaran EKG kedua pasien tersebut yang menunjukkan gambaran hipertrofi ventrikel kiri adalah jumlah gelombang $\mathrm{S}$ pada lead V1 dengan gelombang R pada lead V5/V6 (dipilih yang lebih tinggi) $>35 \mathrm{~mm}$, hal ini sesuai dengan kriteria (Sokolow, M. dan Lyon 1949) untuk hipertrofi ventrikel kiri.

Hanya didapatkan dua gambaran hipertrofi ventrikel kiri dapat disebabkan karena banyak dari pasien yang terdiagnosa hipertrofi ventrikel kiri tidak dilakukan perekaman EKG di hari yang sama dengan penulis mengambil data sehingga rekaman EKG tersebut tidak terdata. Selain itu, jika pada pasien terdapat hipertrofi/pembesaran ventrikel kiri dan ventrikel kanan dengan besar vektor yang sama di mana akan menghasilkan resultan $=0$ maka gambaran EKG yang muncul adalah gambaran EKG normal, sehingga hipertrofi ventrikel kiri tidak dapat terbaca (Aminuddin, 2015).

\section{SIMPULAN DAN SARAN}

\section{Simpulan}

Berdasarkan data pada penelitian ini, jumlah pasien hipertensi secara statistik ditemukan sama pada pria dan wanita, dengan penderita hipertensi paling banyak didapatkan pada rentang usia 5160 tahun. Hal tersebut bertentangan dengan berbagai hasil penelitian sebelumnya yang mangatakan bahwa terdapat perbedaan antara pria dan wanita. 


\section{Saran}

Diperlukan penelitian serupa dengan jumlah subjek penelitian yang lebih banyak dengan lama waktu penelitian lebih panjang serta dengan menggunakan gambaran EKG pasien hipertensi yang lebih dikembangkan, tidak hanya hipertorfi ventrikel kiri saja, mengingat banyak perubahan yang dapat terjadi pada jantung dikarenakan oleh hipertensi.

\section{KEPUSTAKAAN}

JNC-7, 2003. The seventh report of the joint national committee on prevention, detection, evaluation, and treatment of high blood pressure. JAMA, pp.25602571 .

Kannel, W.B., 1983. Prevalence and natural history of electrocardiographic left ventricular hypertrophy. The American Journal of Medicine, 75(3), p.hal. 4-11.

Krummel, D.A., 2004. Medical nutrition therapy in hypertension, dalam: Mahan, L. K. dan Escott-Stump (eds). 200., USA:
Saunders Co.

Muhammadun, A.S., 2010. Hidup bersama hipertensi, Yogyakarta: iN-Books.

Pradono, J., Faktor-faktor yang memengaruhi terjadinya hipertensi di daerah perkotaan (analisis data riskesdas 2007). Gizi Indonesia, 33(1), p.hal. 59-66.

Rampal, L. et al., 2008. Prevalence, awareness, treatment and control of hypertension in Malaysia: a national study of 16,440 subjects. Public Health, 122(1), p.hal. $11-18$.

Setiawan, Z., 2006. Prevalensi dan determinan hipertensi di Pulau Jawa tahun 2004. Kesmas: Jurnal Kesehatan Masyarakat Nasional, , 1(2).

Sokolow, M. dan Lyon, T.P., 1949. The ventricular complex in left ventricular hypertrophy as obtained by unipolar precordial and limbs leads. American Heart Journal, 37(2), p.hal. 161-186.

Susalit, E., 2001. Hipertensi primer dalam: Buku Ajar Ilmu Penyakit Dalam. Ed. 3 Vol., Jakarta: Balai Penerbit FK-UI. 